\title{
Teoria das Representações Sociais e Educação Física: Análise de teses e dissertações defendidas em programas brasileiros de pós-graduação
}

\author{
Social Representations Theory and Physical Education: Analysis of theses and dissertations \\ defended in Brazilian post-graduation programs \\ Teoría de las Representaciones Sociales y Educación Física: Análisis de tesis y disertaciones \\ defendidas en programas de posgrado brasileños
}

Recebido: 17/03/2021 | Revisado: 23/03/2021 | Aceito: 25/03/2021 | Publicado: 02/04/2021

\author{
Everton de Souza \\ ORCID: https://orcid.org/0000-0001-6695-0891 \\ Universidade do Estado de Santa Catarina, Brasil \\ E-mail: everton-sou@hotmail.com \\ Larissa Cerignoni Benites \\ ORCID: https://orcid.org/0000-0001-6144-5298 \\ Universidade do Estado de Santa Catarina, Brasil \\ E-mail: lari.benites@gmail.com
}

\begin{abstract}
Resumo
Esta pesquisa teve como objetivo mapear e analisar as teses e dissertações defendidas entre 2013 e 2020 em programas brasileiros de pós-graduação e que versam sobre as representações sociais e a Educação Física no contexto educacional. No que tange aos aspectos metodológicos, a presente investigação caracteriza-se como uma pesquisa de abordagem quali-quantitativa com delineamento bibliográfico e análise bibliométrica. A busca pelos trabalhos foi realizada na Plataforma Digital Brasileira de Teses e Dissertações e no Catálogo de Teses e Dissertações da Capes por meio dos descritores 'representações sociais' e ‘Educação Física' e com a utilização do operador booleano AND. Após a aplicação de critérios de inclusão e de exclusão, foram selecionados vinte e oito trabalhos para serem analisados com maior profundidade. Os resultados apontam que nos últimos anos houve maior adesão à Teoria das Representações Sociais pelos pós-graduandos brasileiros que pesquisam a Educação Física Escolar. Todavia, destaca-se que ainda é necessário maior apropriação dessa teoria pelos pesquisadores da área.
\end{abstract}

Palavras-chave: Representações sociais; Educação física; Teses e dissertações.

\begin{abstract}
This research focused on mapping and analyzing theses and dissertations defended between 2013 and 2020 in Brazilian post-graduation programs and are related to the social representations and Physical Education in educational context. With regards to methodological aspects, this investigation is characterized as a research of quali-quantitative approach with bibliographic design and bibliometric analysis. The search for the academic productions was made in the Brazilian Digital Platform of Theses and Dissertations and in Theses and Dissertations Catalogue by Capes throughout the descriptors "social representations" and "Physical Education", utilizing the boolean operator AND. After the application of the inclusion and exclusion criteria, twenty-eight academic productions were selected to a deeper analysis. The results show that in recent years there has been greater adherence to the Social Representations Theory by Brazilian graduating students who research Scholar Physical Education. By the way, stands out that still is necessary a greater appropriation of this theory by the researchers in the area.
\end{abstract}

Keywords: Social representations; Physical education; Theses and dissertations.

\section{Resumen}

Esta investigación tuvo como objetivo mapear y analizar las tesis y disertaciones defendidas entre 2013 e 2020 en programas de posgrado brasileños y que abordaron las representaciones sociales y la Educación Física en el contexto educativo. En cuanto a los aspectos metodológicos, la presente pesquisa es caracterizada como una investigación de abordaje quali-cuantitativo con delineamiento bibliográfico y análisis bibliométrico. La búsqueda de los trabajos académicos se realizó en la Plataforma Digital de Tesis y en el Catálogo de Tesis y Disertaciones de Capes utilizando el operador booleano AND. Después de aplicar los criterios de inclusión y exclusión, se seleccionaron veintiocho artículos para ser analizados con mayor profundidad. Los resultados muestran que en los últimos años ha habido una mayor adhesión a la Teoría de las Representaciones Sociales por parte de los estudiantes de posgrado brasileños que investigan en Educación Física Escolar. Sin embargo, es de destacar que aún existe la necesidad de una mayor apropiación de esta teoría por parte de los investigadores en el campo.

Palabras clave: Representaciones sociales; Educación física; Tesis y disertaciones. 


\section{Considerações Iniciais}

A Teoria das Representações Sociais (TRS) surgiu no ano de 1961 por meio da obra 'La Psychanalyse: son image et son public', do francês Serge Moscovici. Na elaboração da teoria, o autor teve grande influência dos pressupostos das representações coletivas durkheimianas, as quais concebem uma cadeia intelectual completa que abrange "[...] ciência, religião, mito, modalidades de tempo e espaço etc. [...]", isto é, qualquer ideia ou crença que ocorresse dentro de um grupo estaria incluída nas representações coletivas (Moscovici, 2003 p.45-46).

Todavia, para Moscovici (Ibidem, 2003), essa definição de representações coletivas apresentava um problema, pois abrangia muitos elementos, sendo que conhecimento e crença eram, em sua visão, extremamente heterogêneos e não deveriam ser reduzidos a características generalizantes, como supõem as representações coletivas. Assim, a partir dessa ideia - com o intuito conhecer as representações com o maior detalhamento possível -, o francês começou a realizar estudos tendo como referência a psicologia social, por compreender que esta encontrava-se centrada na estrutura e na dinâmica das representações. Foi devido a essas diferenças que Moscovici utilizou o termo "sociais" em vez de "coletivas".

Portanto, a TRS reconhece a pluralidade dos sujeitos, atitudes, pensamentos, ideias e fenômenos em toda a sua complexidade, visando sempre elucidar como as pessoas e a comunidade podem construir um mundo com base nas diferenças que as cercam (Moscovici, 2003). Logo, não se trata de uma mera mudança semântica do termo "coletivas" para "sociais", mas de outra qualificação em que "sociais" assume a maneira de ser e produzir sentidos em uma sociedade plural (Oliveira, 2001).

Denise Jodelet caracteriza as representações sociais como "[...] uma forma de conhecimento, socialmente elaborada e partilhada, com um objetivo prático, e que contribui para construção de uma realidade comum a um conjunto social" (Jodelet, 2001, p.22). Para a autora, as representações sociais surgem das experiências coletivas entre os sujeitos e orientam as condutas no cotidiano.

Os estudos que articulam a TRS e a área educacional iniciaram ainda na década de 1980, na França, por meio da obra Maître-élève: rôles institutionnels et représentations ${ }^{l}$, de Michel Gilly. Segundo o autor, as representações sociais possuem um grande potencial para compreender os aspectos que permeiam a educação, pois têm a capacidade de enfatizar as significações existentes no processo pedagógico (Souza; Villas Bôas, 2011). Alves-Mazzotti (1994, p.60) destaca que "[...] por seu papel na orientação de condutas e das práticas sociais, as representações sociais constituem elementos essenciais à análise dos mecanismos que interferem na eficácia do processo educativo". Moreira e Miranda (2019, p.110) acrescentam que as investigações desenvolvidas com o embasamento teórico da TRS permitem a compreensão das subjetividades que "[...] caracterizam e permeiam as histórias de vida dos sujeitos que compõem o cenário educativo". Por surgir nas relações cotidianas e orientar as ações individuais dos sujeitos, o estudo das representações sociais na educação é primordial para que os processos educacionais possam ser compreendidos de maneira mais eficaz.

A importância de investigar as representações sociais na educação estende-se à Educação Física, uma vez que essa disciplina é componente curricular obrigatório na educação básica² ${ }^{2}$ Porém, embora a Educação Física tenha papel fundamental no desenvolvimento integral dos educandos (Lovisolo, 2002; Aguiar, 2003), Vasconcelos e Campos (2014) elucidam que investigações no campo das representações sociais têm mostrado que a Educação Física possui menos prestígio pedagógico quando comparada com as demais disciplinas. Varanda (2018) acrescenta que há muitas ideias nas escolas sobre do que se trata a Educação Física e de que forma ela deve se situar no contexto, e tais ideias abrem lacunas para a criação e sustentação de representações sobre a disciplina.

Portanto, entende-se que os estudos que possuem como aporte teórico a TRS tornam-se essenciais para o campo da Educação Física escolar, uma vez que, para Triani, Magalhães Júnior e Novikoff (2017, p.576), a utilização dessa teoria “[...]

\footnotetext{
${ }^{1}$ Tradução livre: Professor-aluno: papéis institucionais e representações.

${ }^{2}$ Facultativa em algumas situações, conforme Lei n ${ }^{\circ}$ 9394/96.
} 
vem mostrando seu valor num duplo papel da pesquisa científica. O primeiro refere-se à necessidade de se compreender a realidade em que se pretende realizar a pesquisa, já o segundo consiste em intervir na realidade que se propõe a compreender". Freitas, Triani e Novikoff (2017) salientam que é indispensável situar-se em relação às representações sociais que permeiam a Educação Física escolar e à maneira como elas influenciam os processos pedagógicos.

Considerando o exposto, as aulas de Educação Física apresentam-se como um ambiente em que inúmeras representações podem ser construídas e transformadas, devido ao fato de as especificidades da disciplina comumente possibilitarem a ocorrência de muitas interações entre os alunos. Além do mais, nas aulas - por meio de debates - podem ser abordadas diversas temáticas contemporâneas e históricas da área, o que permite a ressignificação ou a reafirmação das concepções dos alunos sobre os temas, assim como tensionar as concepções do próprio professor perante os diálogos estabelecidos. Isso se deve ao fato de que, de acordo com Mello et al (2012, p.446), “[...] qualquer que seja a representação, ela é identitária, no sentido de que se constrói em referência à história do sujeito, suas expectativas, concepção de mundo, relações com os outros e consigo mesmo". Logo, todos os sujeitos estão à mercê de terem suas representações afetadas pelas interações existentes na Educação Física escolar.

Todavia, a Educação Física enquanto área de estudo parece não estar se apropriando de maneira satisfatória das contribuições que podem ser proporcionadas pelos estudos das representações sociais, pois, como Triani e Novikoff (2014, p.96) defendem, “[...] a apropriação da TRS pela produção científica da Educação Física brasileira ainda é tímida".

Em levantamento bibliográfico realizado por Triani e Novikoff (2014), os autores encontraram apenas oito teses e dissertações - disponibilizadas no site da Coordenação de Aperfeiçoamento de Pessoal de Nível Superior (CAPES) e publicadas entre os anos de 2000 e 2012 - que abordaram as representações sociais na área da Educação Física. Levando em consideração o recorte histórico do estudo - mais de uma década -, consideramos baixo o número de investigações desenvolvidas nos programas de pós-graduação do país sobre a temática supracitada.

Entretanto, para Triani e Novikoff (2014, p.96), foi possível observar “[...] uma maior consistência teórica ao longo dos anos, perspectivando uma melhora qualitativa nos estudos em representações sociais na Educação Física". Segundo os autores, tal fato evidencia novas maneiras de perceber os fenômenos presentes nas aulas de Educação Física, colaborando para uma maior compreensão da disciplina e para possíveis intervenções dos professores.

Assim, para compreender melhor a produção acadêmica no que tange à TRS e à Educação Física, essa pesquisa teve como objetivo mapear e analisar teses e dissertações defendidas em programas brasileiros de pós-graduação entre 2013 e 2020 que versam sobre as representações sociais e a Educação Física no contexto educacional. O recorte histórico escolhido justificase pela necessidade de constatar se houve alguma alteração no cenário apresentado por Triani e Novikoff (2014) em relação ao baixo número de teses e dissertações que discorreram sobre a Educação Física sob a perspectiva da TRS.

\section{Encaminhamentos Metodológicos}

Essa pesquisa possui abordagem qualitativa com delineamento bibliográfico e se valeu de alguns elementos quantitativos por meio da análise bibliométrica (Pereira et al, 2018). Os textos científicos analisados foram teses e dissertações defendidas em programas brasileiros de pós-graduação. A adesão pela revisão bibliográfica com análise bibliométrica justificase, como explica Gomes et al (2008), pelo fato de que o mapeamento e a avaliação do conhecimento acadêmico se apresentam como uma necessidade constante devido à produção científica estar em contínuo desenvolvimento.

As buscas pelos trabalhos foram realizadas na base de dados da Biblioteca Digital Brasileira de Teses e Dissertações (BDTD) e do Catálogo de Teses e Dissertações da Capes por meio dos seguintes descritores: "representações sociais" e "Educação Física".

Utilizamos o operador booleano AND para restringir a busca a teses e dissertações que apresentassem os dois descritores investigados. Portanto, a pesquisa foi realizada com a seguinte combinação: "representações sociais" AND "Educação Física". 
A seleção das teses e dissertações foi realizada por meio dos seguintes critérios de inclusão: a) a defesa do trabalho ter sido realizada entre os anos de 2013 e 2020 em programa brasileiro de pós-graduação; b) o trabalho possuir divulgação autorizada pelo pós-graduando; e c) o trabalho ter enfoque nas representações sociais e na Educação Física no contexto educacional. Os critérios de exclusão adotados foram: a) trabalhos com resultados duplicados; b) trabalhos com inconsistência de informações; e c) não atender aos três critérios de inclusão.

Os resumos de todos os trabalhos encontrados foram lidos na íntegra. Também foi realizada uma busca de outras informações no corpo das teses e dissertações para constatar se atendiam aos critérios de inclusão adotados.

\section{Resultados e Discussões}

A busca na BDTD foi realizada no dia 03 de dezembro de 2020. Foram encontrados trinta e quatro resultados, defendidos entre os anos de 2013 e 2020, contendo os descritores "representações sociais" e "Educação Física".

Entretanto, após uma primeira análise, contatamos que havia uma dissertação que foi cadastrada duas vezes na BDTD e uma tese que foi cadastrada três vezes. Os trabalhos com cadastro duplicado foram considerados como um resultado cada.

A dissertação de mestrado intitulada "Representações sociais da comunidade escolar de Cachoeiro de Itapemirim sobre o que é ser um bom professor de Educação Física" foi desconsiderada ao constatarmos que houve um erro em seu cadastro na plataforma da BDTD, pois a defesa ocorreu no ano de 2007 e não em 2017, como está descrito na base. Constatamos a mesma inconsistência ao verificar a ficha catalográfica da tese de doutorado "Métodos de recuperação pós-exercício: efeitos sobre marcadores fisiológicos, psicológicos, bioquímicos, imunológicos, de desempenho, e sentidos aplicados por sujeitos treinados", que foi defendida no ano de 2012 e não em 2013.

Dessa maneira, foram consideradas da busca inicial na Biblioteca Digital vinte e nove das produções com os descritores "representações sociais" e "Educação Física". Todas as teses e dissertações encontradas na BDTD possuem divulgação autorizada pelos autores.

No dia 14 de dezembro de 2020, realizamos a busca no Catálogo de Teses e Dissertações da Capes. Foram encontrados 109 trabalhos.

Ao analisarmos as informações disponíveis sobre as teses e dissertações, verificamos que quarenta e nove trabalhos defendidos na Universidade Federal do Rio Grande do Sul (UFRGS) foram desenvolvidos na linha de pesquisa "Representações Sociais do Movimento Humano", a qual pertence ao Programa de Pós-Graduação em Ciências do Movimento Humano. Desses quarenta e nove trabalhos, constatamos que quarenta e sete não possuíam as representações sociais e a Educação Física como descritores. Essas produções apareceram entre os resultados porque tinham "Educação Física" como descritor no corpo do texto da tese ou dissertação e a expressão "representações sociais" descrita nas informações sobre o trabalho na página do Catálogo de Teses e Dissertações, na opção da linha de pesquisa em que foi realizada a investigação. Dessa maneira, optamos por desconsiderar da busca inicial esses quarenta e sete trabalhos. Ainda, houve o encontro da tese de doutorado com data de defesa equivocada, tal como na BDTD, e oito trabalhos que não possuíam divulgação autorizada pelos pós-graduandos.

Ao compararmos os resultados da busca realizada no banco de dados da BDTD com os resultados do Catálogo de Teses e Dissertações da Capes, constatamos que houve a duplicação de quinze teses e dissertações. Dessa maneira, foram considerados trinta e oito trabalhos da busca realizada no Catálogo de Teses e Dissertações com os descritores "representações sociais" e "Educação Física".

Portanto, o resultado final da busca em ambas as plataformas contou com um total de sessenta e sete trabalhos defendidos - quatorze teses e cinquenta e três dissertações - entre 2013 e 2020.

Considerando o escopo dessa pesquisa, analisamos os sessenta e sete trabalhos para selecionar os que apresentavam as representações sociais e a Educação Física como objeto de pesquisa. Para tal, os resumos foram lidos e informações foram 
buscadas no corpo do texto de todas as produções, e, nesse processo, houve a exclusão de vinte e oito trabalhos, pois, apesar de possuírem ambos os descritores, não possuíam o enfoque nas representações sociais e na Educação Física.

Durante esse processo de leitura, notamos que outras onze produções possuíam as representações sociais e a área da Educação Física como objeto de estudo, entretanto não abordavam o contexto educacional, que é foco dessa pesquisa e, por conseguinte, foram excluídas.

Um total de vinte e oito trabalhos - quatro teses e vinte e quatro dissertações - atenderam aos três critérios de inclusão e foram selecionados para uma análise mais detalhada. No Gráfico 1, apresenta-se os tipos de trabalhos e os respectivos anos em que foram defendidos.

Gráfico 1. quantidade e ano de defesa das teses e dissertações que abordam as representações sociais e a Educação Física no contexto educacional entre os anos de 2013 e 2020, conforme o ano de defesa.

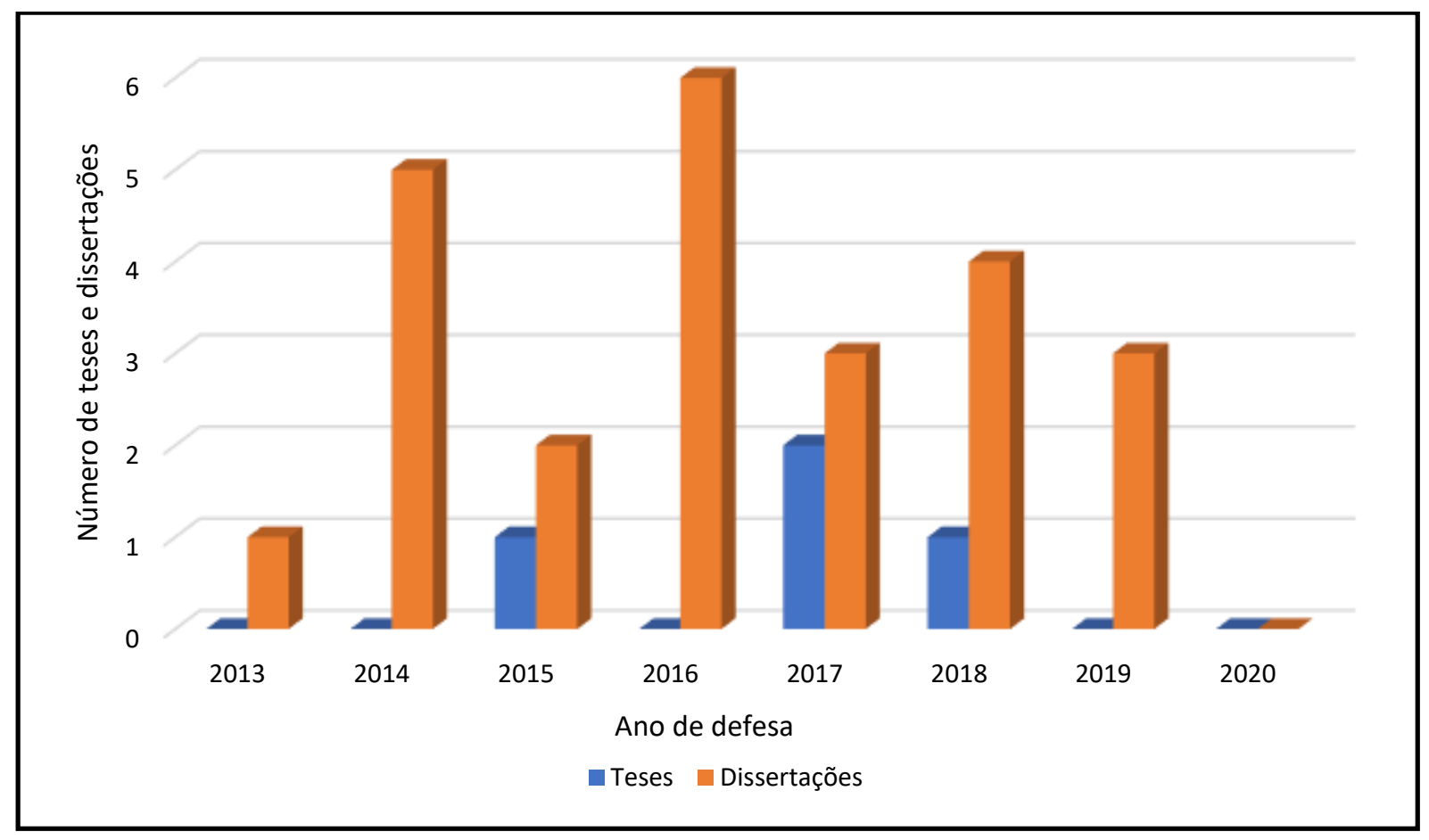

Fonte: Autores.

Em relação ao ano de 2020, destacamos que pode ser que teses e dissertações com a temática pesquisada tenham sido defendidas, mas ainda não tinham sido cadastradas nas bases de dados nas datas em que as pesquisas foram realizadas.

Assim, obteve-se um corpus de 28 estudos, que estão descritos no Tabela 1, no qual pode-se verificar os autores, os tipos de produção e os títulos e objetivos das teses e dissertações analisadas com maior profundidade. 
Tabela 1. autor, tipo de produção, título e objetivo das teses e dissertações que versam sobre as representações sociais e a Educação Física no campo educacional entre os anos de 2013 e 2020.

\begin{tabular}{|c|c|}
\hline Autor & Título \\
\hline $\begin{array}{l}\text { Guarinon } \\
\text { (2016). }\end{array}$ & $\begin{array}{l}\text { Representações Sociais e o Currículo de } \\
\text { Educação Física: com a palavra os alunos. }\end{array}$ \\
\hline $\begin{array}{l}\text { Triani } \\
(2015)\end{array}$ & $\begin{array}{l}\text { As Representações Sociais de Estudantes de } \\
\text { Educação Física sobre o Corpo. }\end{array}$ \\
\hline $\begin{array}{l}\text { Lobato } \\
(2015)\end{array}$ & $\begin{array}{l}\text { "No que você está pensando?" Representações } \\
\text { Sociais de Corpo de Professores de Educação } \\
\text { Física Usuários do Facebook. }\end{array}$ \\
\hline $\begin{array}{l}\text { Gregório } \\
\text { (2014). }\end{array}$ & $\begin{array}{l}\text { As Representações Sociais de Corpos } \\
\text { Femininos: a perspectiva de crianças. }\end{array}$ \\
\hline $\begin{array}{l}\text { Stroher } \\
(2014) \text {. }\end{array}$ & $\begin{array}{l}\text { O Trabalho com o Corpo/Aluno na Educação } \\
\text { Física Escolar Sob a Ótica dos Discentes do } \\
\text { Curso de Licenciatura em Educação Física da } \\
\text { UNEMAT/ Cáceres: um estudo de } \\
\text { representações sociais. }\end{array}$ \\
\hline $\begin{array}{l}\text { Sales } \\
(2018)\end{array}$ & $\begin{array}{l}\text { As Representações Sociais da Educação Física, } \\
\text { em Espaços Formais e Não Formais, na } \\
\text { Perspectiva de Jovens do Ensino Médio. }\end{array}$ \\
\hline
\end{tabular}

Jesus Representações Sociais de Professores Sobre a

(2014). Inserção / Intervenção Pedagógica da Educação Física na Educação Infantil de Serra.

Lima Representações Sociais e Práticas de Lazer de

(2013). Estudantes e Professores de uma Escola de Educação Integral do Rio de Janeiro.

Medeiros “Que Autonomia é Essa?": uma etnografia com

(2016). os professores de uma escola da rede municipal de ensino de Porto Alegre -RS.

Rosa Representações sociais das lutas para alunos da

(2019). rede pública de ensino de Angra dos Reis - RJ.

Santos Representação Social do Desenvolvimento

(2016). Psicomotor Elaborada por Professores de Educação Física.

Caramez Representações Sociais de Formação

(2016). Pedagógica de Alunos de Curso de Licenciatura em Educação Física.

Lima Representações Sociais da Capoeira: o cenário

(2014). em escolas de Maringá

Savarezzi Representações Sociais sobre o Componente

(2017). Curricular Educação Física: uma comparação entre o Ensino Fundamental e o Ensino Médio.

\begin{tabular}{cll} 
Monteiro & \multicolumn{4}{l}{ Representações Sociais, Docência e Práticas em } \\
(2016). & Educação Física nas $\begin{array}{c}\text { Escolas } \\
\text { Rurais/Campo/Roça do Município de Cunha, } \\
\text { SP. }\end{array}$ \\
Ordonio & $\begin{array}{l}\text { Representações Sociais dos Professores de } \\
\text { (2017). }\end{array}$ & $\begin{array}{l}\text { Educação Física Escolar Sobre a } \\
\text { Psicomotricidade. }\end{array}$ \\
\end{tabular}

\section{Objetivo}

Identificar as Representações Sociais dos alunos de uma escola Rede Estadual de Ensino, no Município de Santo André, sobre o componente curricular Educação Física.

Investigar as tendências das representações sociais de corpo na formação inicial de professores de Educação Física (licenciatura).

Analisar as representações de corpo de professores graduados em Educação Física usuários do Facebook.

Analisar representações sociais de crianças sobre corpos femininos estabelecendo relações com práticas corporais vivenciadas em aulas de Educação Física de uma escola de ensino fundamental da rede pública de Brasília.

Encontrar e analisar as representações sociais que os discentes do curso de Licenciatura em Educação Física da Universidade do Estado de Mato Grosso - UNEMAT campus Jane Vanini Cáceres/MT possuem acerca do trabalho com o corpo na escola.

Compreender as representações

sociais da Educação Física, em espaços formais e não formais, na perspectiva dos jovens do

Ensino Médio.

Identificar e analisar as representações sociais de professores sobre a inserção/intervenção da Educação Física no contexto da Educação Infantil de Serra/ES.

Investigar as Representações Sociais (RS) de educação integral e lazer na perspectiva de estudantes e professores, no contexto da educação integral.

Compreender como se configura a autonomia de professores de Educação Física em uma cultura particular na Rede Municipal de Ensino de Porto Alegre.

Identificar as representações sociais que alunos de educação física, do segundo segmento do ensino fundamental, da rede pública do município de Angra dos Reis - RJ, possuem acerca das lutas.

Identificar e conhecer a organização da representação social do desenvolvimento psicomotor elaborado por professores de Educação Física Escolar.

Investigar e comparar as representações sociais de formação pedagógica de alunos dos últimos períodos do curso de licenciatura em Educação Física de duas Universidades distintas sendo uma pública e outra privada.

Investigar as representações sociais da Capoeira por parte de professores de Educação Física e estudantes do ensino fundamental e médio em escolas da rede pública estadual. Identificar, compreender e comparar as representações sociais dos alunos de Ensino Fundamental e Médio sobre a Educação Física, no intuito de apreender o papel que estas exercem no processo de ensino e aprendizagem dos alunos nas aulas deste componente curricular.

Investigar as representações sociais de professores que ministram aula de Educação Física sobre o contexto e a prática de ensinar a disciplina nas escolas do campo/rural/roça.

Identificar e analisar as representações sociais produzidas pelos professores de educação física escolar sobre psicomotricidade. 


\begin{tabular}{|c|c|c|}
\hline $\begin{array}{l}\text { Varanda } \\
\text { (2018). }\end{array}$ & $\begin{array}{l}\text { As Representações Sociais de Educação Física } \\
\text { na Visão de Diferentes Atores Escolares: } \\
\text { alunos, professores e gestores. }\end{array}$ & $\begin{array}{l}\text { Identificar e analisar as representações sociais sobre a } \\
\text { Educação Física escolar, por parte dos atores escolares } \\
\text { (docentes, equipe gestora e alunos). }\end{array}$ \\
\hline $\begin{array}{l}\text { Costa } \\
(2017)\end{array}$ & $\begin{array}{l}\text { As Relações Entre Desigualdades de Gênero e } \\
\text { Autoexclusão de Alunas das Aulas de Educação } \\
\text { Física no Ensino Médio. }\end{array}$ & $\begin{array}{l}\text { Discutir a influência das desigualdades de gênero no processo } \\
\text { de autoexclusão de alunas das aulas de Educação Física no } \\
\text { Ensino Médio. }\end{array}$ \\
\hline $\begin{array}{l}\text { Siqueira } \\
(2019) .\end{array}$ & $\begin{array}{l}\text { As Representações Sociais de Alunos Sobre a } \\
\text { Transição do } 5^{\circ} \text { para o } 6^{\circ} \text { Ano do Ensino } \\
\text { Fundamental e a Educação Física. }\end{array}$ & $\begin{array}{l}\text { Analisar as representações sociais dos alunos sobre a transição } \\
\text { do } 5^{\circ} \text { para o } 6^{\circ} \text { ano e a Educação Física. }\end{array}$ \\
\hline $\begin{array}{l}\text { Nascimento } \\
\text { (2018). }\end{array}$ & $\begin{array}{l}\text { Dos Filtros do Instagram à Quadra da Escola: } \\
\text { representações sociais do corpo na perspectiva } \\
\text { dos/as adolescentes. }\end{array}$ & $\begin{array}{l}\text { Compreender como os/as adolescentes pensam o corpo, na } \\
\text { perspectiva das RS, em contextos como a Educação Física } \\
\text { Escolar e o Instagram. }\end{array}$ \\
\hline $\begin{array}{l}\text { Polati } \\
(2019) \text {. }\end{array}$ & $\begin{array}{l}\text { Representações Sociais de Licenciandos de } \\
\text { Educação Física Sobre o Estágio Curricular } \\
\text { Supervisionado. }\end{array}$ & $\begin{array}{l}\text { Identificar as representações sociais dos licenciandos do curso } \\
\text { de Licenciatura em Educação Física sobre o ECS, visando } \\
\text { compreender as suas atitudes frente ao desenvolvimento deste } \\
\text { componente curricular. }\end{array}$ \\
\hline $\begin{array}{l}\text { Martins } \\
\text { (2014). }\end{array}$ & $\begin{array}{l}\text { Representações das Aulas de Educação Física } \\
\text { para Alunos da Educação de Jovens e Adultos } \\
\text { no II Segmento e o Trabalho Docente. }\end{array}$ & $\begin{array}{l}\text { Avaliar os efeitos da aplicação de uma proposta pedagógica } \\
\text { nas aulas de Educação Física na modalidade EJA. }\end{array}$ \\
\hline $\begin{array}{l}\text { Paula } \\
(2018) \text {. }\end{array}$ & $\begin{array}{l}\text { As Representações Sociais de Alunos e de } \\
\text { Professores Acerca do Corpo nas Aulas de } \\
\text { Educação Física Escolar. }\end{array}$ & $\begin{array}{l}\text { Investigar as representações sociais acerca do corpo nas aulas } \\
\text { de Educação Física escolar, tanto de alunos como de } \\
\text { professores desse componente curricular, ambos, } \\
\text { respectivamente, discentes e docentes de uma mesma escola } \\
\text { de Ensino Fundamental. }\end{array}$ \\
\hline $\begin{array}{l}\text { Engeroff } \\
(2016) \text {. }\end{array}$ & $\begin{array}{l}\text { As Representações da Educação Física Escolar } \\
\text { no Ensino Médio: um estudo de caso. }\end{array}$ & $\begin{array}{l}\text { Compreender quais e como são construídas as representações } \\
\text { conferidas à Educação Física em uma escola de Ensino Médio } \\
\text { da Rede Estadual de Ensino do RS. }\end{array}$ \\
\hline \multicolumn{3}{|c|}{ Teses } \\
\hline Autor & Título & Objetivo \\
\hline $\begin{array}{c}\text { Sá } \\
(2015) \text {. }\end{array}$ & $\begin{array}{l}\text { O Professor do Primeiro Ano do Ensino } \\
\text { Fundamental e Suas Representações Socais } \\
\text { Sobre o Movimento Corporal. }\end{array}$ & $\begin{array}{l}\text { Identificar e analisar as representações sociais de um grupo de } \\
\text { professores de algumas escolas públicas do município de São } \\
\text { Bernardo do Campo a respeito do movimento corporal da } \\
\text { criança do } 1^{\circ} \text { ano do Ensino Fundamental. }\end{array}$ \\
\hline $\begin{array}{l}\text { Honorato } \\
\text { (2017). }\end{array}$ & $\begin{array}{l}\text { As Representações Socais dos Acadêmicos do } \\
\text { Curso de Licenciatura em Educação Física } \\
\text { Sobre o que é Ser Professor. }\end{array}$ & $\begin{array}{l}\text { Analisar as representações sociais dos acadêmicos do Curso } \\
\text { de Licenciatura em Educação Física em relação a sua } \\
\text { formação profissional, ao que é Ser professor e Ser professor } \\
\text { Educação Física, a partir dos pressupostos teóricos } \\
\text { metodológicos da Teoria das Representações Sociais }\end{array}$ \\
\hline $\begin{array}{l}\text { Martins } \\
(2018) \text {. }\end{array}$ & $\begin{array}{l}\text { O Lugar da Educação Física na Educação } \\
\text { Infantil. }\end{array}$ & $\begin{array}{l}\text { Analisar as formas que têm caracterizado as relações da } \\
\text { Educação Física com a Educação Infantil, por diferentes } \\
\text { dimensões. }\end{array}$ \\
\hline $\begin{array}{l}\text { Almeida } \\
\text { (2017). }\end{array}$ & $\begin{array}{l}\text { Docência Superior e Representações Sociais no } \\
\text { Campo da Educação Física Escolar: narrativas } \\
\text { de professores do curso de Licenciatura. }\end{array}$ & $\begin{array}{l}\text { Conhecer e discutir o campo de conhecimentos sobre EFE, em } \\
\text { doutores que atuam na Licenciatura, tendo por base as RS, } \\
\text { concebidas como estados de 'preparação para a ação' em uma } \\
\text { "rede de relações". }\end{array}$ \\
\hline
\end{tabular}

Fonte: Autores.

No que se refere aos objetos investigados nas teses e dissertações inclusas, observou-se uma predominância de temas referentes às representações sociais sobre a Educação Física (Sales, 2018; Jesus, 2014; Martins, 2018; Savarezzi, 2017; Monteiro, 2016; Varanda, 2018; Martins, 2014; Engeroff, 2016) e sobre o Corpo (Triani, 2015; Lobato, 2015; Gregório, 2014; Stroher, 2014; Sá, 2015; Nascimento, 2018; Paula, 2018). Os objetos e contextos de pesquisa das teses e dissertações que versam sobre as representações sociais e a área da Educação Física no contexto educacional estão descritos no Tabela 2: 
Tabela 2. Objeto e contexto das teses e dissertações que versam sobre as representações sociais e a Educação Física.

\begin{tabular}{|c|c|c|}
\hline Autor & Objeto & Contexto \\
\hline Guarinon (2016). & Currículo da Educação Física. & Educação Básica. \\
\hline Triani (2015). & Corpo e formação docente. & Ensino superior. \\
\hline Lobato (2015). & Corpo e mídia social. & Educação básica. \\
\hline Gregório (2014). & Corpo feminino. & Educação básica. \\
\hline Stroher (2014). & Corpo e escola. & Ensino superior. \\
\hline Sales (2018). & $\begin{array}{l}\text { Educação Física em espaços formais } \\
\text { e não formais. }\end{array}$ & Educação básica. \\
\hline Jesus (2014). & $\begin{array}{l}\text { Educação Física na educação } \\
\text { infantil. }\end{array}$ & Educação básica. \\
\hline Sá (2015). & Corpo e Movimento & Educação básica. \\
\hline Honorato (2017). & Ser Professor. & Ensino superior. \\
\hline Martins (2018). & $\begin{array}{c}\text { Educação Física na educação } \\
\text { infantil. }\end{array}$ & Educação básica. \\
\hline Lima (2013). & Educação integral e lazer. & Educação básica. \\
\hline Medeiros (2016). & Autonomia docente. & Educação básica. \\
\hline Almeida (2017). & Formação docente. & Ensino superior \\
\hline Rosa (2019). & Conteúdo lutas. & Educação básica. \\
\hline Santos (2016). & Desenvolvimento psicomotor. & Educação básica. \\
\hline Caramez (2016). & Formação pedagógica. & Ensino superior. \\
\hline Lima (2014). & Capoeira. & Educação básica. \\
\hline Savarezzi (2017). & $\begin{array}{l}\text { Educação Física na Educação } \\
\text { Básica. }\end{array}$ & Educação básica. \\
\hline Monteiro (2016). & $\begin{array}{l}\text { Educação Física em escolas do } \\
\text { campo }\end{array}$ & Educação básica. \\
\hline Ordonio (2017). & Psicomotricidade. & Educação básica. \\
\hline Varanda (2018) & $\begin{array}{c}\text { Educação Física na educação } \\
\text { básica. }\end{array}$ & Educação básica. \\
\hline Costa (2017). & Desigualdade de gênero. & Educação básica. \\
\hline Siqueira (2019) & Transição no ensino fundamental. & Educação básica. \\
\hline Nascimento (2018). & Corpo. & Educação básica. \\
\hline Polati (2019). & Estágio supervisionado. & Ensino superior. \\
\hline Martins (2014). & $\begin{array}{l}\text { Educação Física na Educação de } \\
\text { Jovens e Adultos. }\end{array}$ & Educação básica. \\
\hline Paula (2018). & Corpo. & Educação básica. \\
\hline Engeroff (2016). & Educação Física no ensino médio. & Educação básica. \\
\hline
\end{tabular}

Fonte: Autores.

Embora exista uma predominância de estudos relacionados às representações sociais sobre a Educação Física e sobre o Corpo, é perceptível que os objetos pelos quais os autores se apropriaram em seus estudos foram muito diversificados, inclusive os próprios objetos Educação Física e Corpo, ao serem investigados, foram relacionados a diferentes contextos e temas da área educacional. Ao construirmos uma nuvem de palavras no Pro Word Cloud do Office 2016 da Microsoft, a heterogeneidade dos objetos pesquisados nas teses e dissertações ficou mais clara, pois a palavra Educação é a que ganha maior destaque na nuvem, uma vez que está relacionada a diversos outros termos dos objetos das pesquisas. Já a palavra Física [Educação Física] e Corpo também se destacam por serem objetos de pesquisa de sete produções cada. As demais palavras demonstram a diversidade de objetos investigados nas teses e dissertações analisadas. 
Imagem 1. nuvem de palavras dos objetos das teses e dissertações.

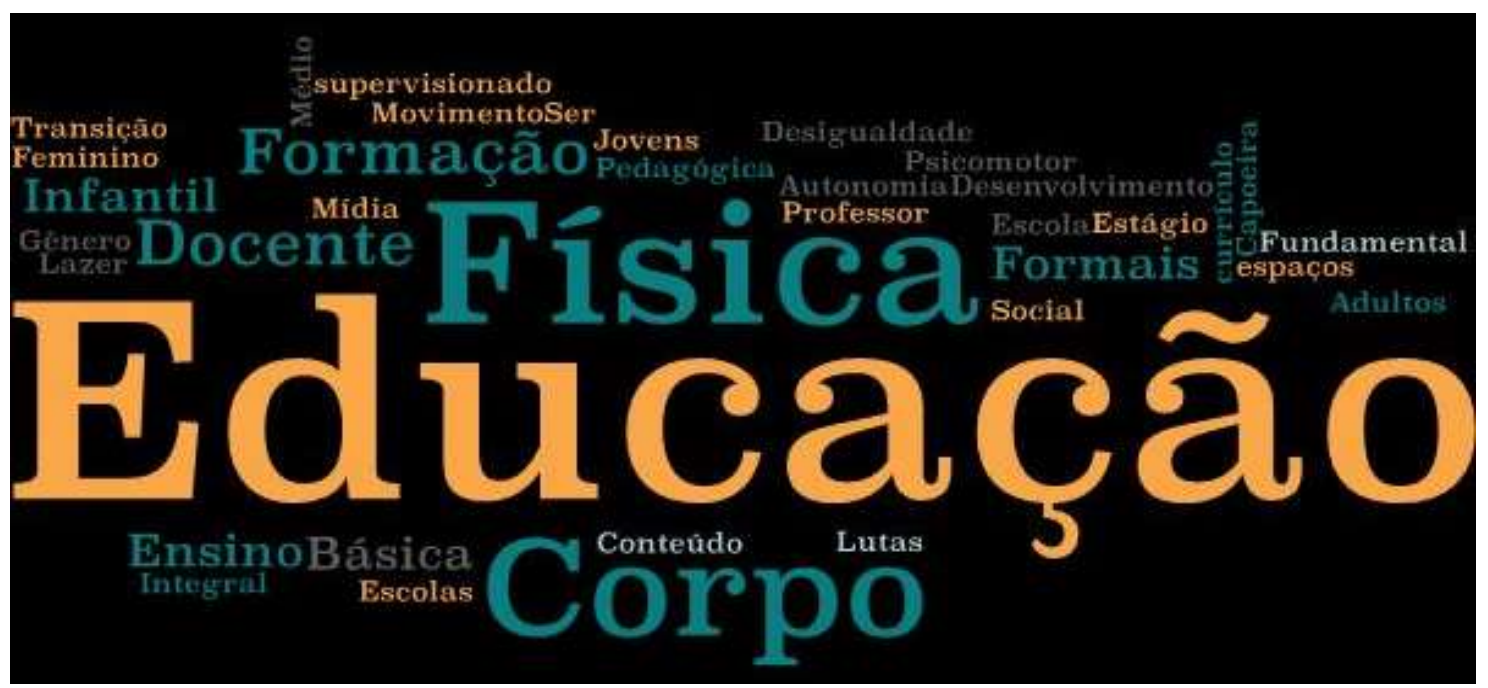

Fonte: Autores.

As investigações focaram, sobretudo, na análise de aspectos referentes ao contexto da educação básica, pois vinte e duas investigações tiveram esse propósito, enquanto apenas seis pesquisaram aspectos relacionados ao contexto do ensino superior.

Quando se pensa na relação dessas produções com os programas de pós-graduação, pode-se notar que os programas relacionados à Educação Física dividiram o protagonismo com os programas em Educação, conforme pode ser observado no Tabela 3:

Tabela 3. programas, universidades e unidades federativas em que foram desenvolvidas as teses e dissertações que versam sobre as representações sociais e a Educação Física.

\begin{tabular}{|c|c|c|c|}
\hline $\begin{array}{l}\text { Programa de Pós- } \\
\text { Graduação }\end{array}$ & Autor & Universidade & Estado \\
\hline Ciências & $\begin{array}{l}\text { Guarinon } \\
\text { (2016). }\end{array}$ & Universidade de São Paulo - USP. & $\mathrm{SP}$ \\
\hline \multirow{2}{*}{$\begin{array}{c}\text { Humanidades, Cultura e } \\
\text { Artes }\end{array}$} & Triani (2015). & $\begin{array}{l}\text { Universidade de Grande Rio - } \\
\text { UNIGRANRIO. }\end{array}$ & RJ \\
\hline & $\begin{array}{l}\text { Paula } \\
(2018)\end{array}$ & $\begin{array}{l}\text { Universidade de Grande Rio - } \\
\text { UNIGRANRIO. }\end{array}$ & RJ \\
\hline \multirow{8}{*}{ Educação Física } & $\begin{array}{l}\text { Lobato } \\
(2015) \text {. }\end{array}$ & Universidade de Brasília - UNB. & $\mathrm{DF}$ \\
\hline & $\begin{array}{l}\text { Gregório } \\
\text { (2014). }\end{array}$ & Universidade de Brasília - UNB. & $\mathrm{DF}$ \\
\hline & $\begin{array}{l}\text { Jesus } \\
(2014) .\end{array}$ & $\begin{array}{c}\text { Universidade Federal do Espírito Santo - } \\
\text { UFES. }\end{array}$ & ES \\
\hline & $\begin{array}{l}\text { Martins } \\
(2018)\end{array}$ & $\begin{array}{l}\text { Universidade Federal do Espírito Santo - } \\
\text { UFES. }\end{array}$ & $\mathrm{ES}$ \\
\hline & $\begin{array}{l}\text { Nascimentos } \\
\quad(2018)\end{array}$ & $\begin{array}{l}\text { Universidade Federal do Vale do São } \\
\text { Francisco - UNIVASF. }\end{array}$ & $\mathrm{PE}$ \\
\hline & $\begin{array}{l}\text { Stroher } \\
(2014) \text {. }\end{array}$ & $\begin{array}{l}\text { Universidade Federal de Mato Grosso - } \\
\text { UFMT. }\end{array}$ & MT \\
\hline & $\begin{array}{l}\text { Sales } \\
(2018)\end{array}$ & $\begin{array}{c}\text { Pontifícia Universidade Católica de Goiás - } \\
\text { PUC/GO. }\end{array}$ & GO \\
\hline & $\begin{array}{c}\text { Sá } \\
(2015) \text {. }\end{array}$ & $\begin{array}{l}\text { Pontifícia Universidade Católica de São } \\
\text { Paulo - PUC/SP. }\end{array}$ & SP \\
\hline
\end{tabular}




\begin{tabular}{|c|c|c|c|}
\hline \multirow{9}{*}{ Educação } & $\begin{array}{l}\text { Honorato } \\
\text { (2017). }\end{array}$ & $\begin{array}{l}\text { Universidade Estadual de Ponta Grossa - } \\
\text { UEPG. }\end{array}$ & PR \\
\hline & $\begin{array}{l}\text { Lima } \\
\text { (2013). }\end{array}$ & Universidade de Brasília - UNB. & $\mathrm{DF}$ \\
\hline & $\begin{array}{l}\text { Almeida } \\
(2017)\end{array}$ & Universidade Estácio de Sá - UNESA. & RJ \\
\hline & $\begin{array}{l}\text { Santos } \\
\text { (2016). }\end{array}$ & Universidade Estácio de Sá - UNESA. & RJ \\
\hline & $\begin{array}{l}\text { Caramez } \\
(2016)\end{array}$ & Universidade Estácio de Sá - UNESA. & RJ \\
\hline & $\begin{array}{r}\text { Lima } \\
(2014)\end{array}$ & Universidade Estadual de Maringá - UEM. & PR \\
\hline & $\begin{array}{l}\text { Savarezzi } \\
(2017)\end{array}$ & $\begin{array}{l}\text { Universidade Cidade de São Paulo - } \\
\text { UNICID. }\end{array}$ & SP \\
\hline & $\begin{array}{l}\text { Polati } \\
(2019)\end{array}$ & $\begin{array}{l}\text { Universidade Federal Rural do Rio de } \\
\text { Janeiro - UFRRJ. }\end{array}$ & RJ \\
\hline & $\begin{array}{l}\text { Martins } \\
(2014)\end{array}$ & Universidade Federal de Alagoas - UFAL. & $\mathrm{AL}$ \\
\hline \multirow{2}{*}{$\begin{array}{l}\text { Ciências do Movimento } \\
\text { Humano }\end{array}$} & $\begin{array}{l}\text { Medeiros } \\
(2016)\end{array}$ & $\begin{array}{c}\text { Universidade Federal do Rio Grande do Sul } \\
\text { - UFRGS. }\end{array}$ & RS \\
\hline & $\begin{array}{l}\text { Engeroff } \\
(2016)\end{array}$ & $\begin{array}{c}\text { Universidade Federal do Rio Grande do Sul } \\
- \text { - UFRGS. }\end{array}$ & $\mathrm{RS}$ \\
\hline Psicologia & $\begin{array}{c}\text { Rosa } \\
(2019)\end{array}$ & $\begin{array}{l}\text { Universidade Federal Rural do Rio de } \\
\text { Janeiro - UFRRJ. }\end{array}$ & RJ \\
\hline $\begin{array}{c}\text { Educação e Desenvolvimento } \\
\text { Humano }\end{array}$ & $\begin{array}{l}\text { Monteiro } \\
(2016) \text {. }\end{array}$ & Universidade de Taubaté - UNITAU. & SP \\
\hline Psicologia Educacional & $\begin{array}{l}\text { Ordonio } \\
(2017)\end{array}$ & Centro Universitário FIEO - UNIFIEO. & SP \\
\hline Ciências da Motricidade & $\begin{array}{l}\text { Varanda } \\
(2018)\end{array}$ & $\begin{array}{l}\text { Universidade Estadual Paulista Júlio de } \\
\text { Mesquita Filho - UNESP. }\end{array}$ & SP \\
\hline Ciências da Atividade Física & $\begin{array}{l}\text { Costa } \\
(2017)\end{array}$ & $\begin{array}{l}\text { Universidade Salgado de Oliveira - } \\
\text { UNIVERSO. }\end{array}$ & RJ \\
\hline $\begin{array}{l}\text { Docência para a Educação } \\
\text { Básica }\end{array}$ & $\begin{array}{l}\text { Siqueira } \\
(2019)\end{array}$ & $\begin{array}{l}\text { Universidade Estadual Paulista Júlio de } \\
\text { Mesquita Filho - UNESP. }\end{array}$ & SP \\
\hline
\end{tabular}

Fonte: Autores.

No que tange às universidades em que foram defendidas as teses e dissertações, as instituições estão localizadas principalmente na região Sudeste. Um total de onze universidades situam-se nessa região do país: São Paulo (USP, PUC-SP, UNICID, UNITAU, UNIFEO e UNESP), Rio de Janeiro (UNIGRANRIO, UNESA, UFRRJ e UNIVERSO) e Espírito Santo (UFES). Na região Sul estão localizadas três instituições: Paraná (UEPG e UEM) e Rio Grande do Sul (UFRGS). No CentroOeste estão situadas outras três: Distrito Federal (UNB), Mato Grosso (UFMT) e Goiás (PUC-GO). E no Nordeste estão localizadas duas: Pernambuco (UNIVASF) e Alagoas (UFAL).

A maior quantidade de produções defendidas em instituições da região Sudeste pode ser compreendida pela maior concentração de universidades nessa região, e destaca-se que "[...] o padrão regional da distribuição das publicações e dos pesquisadores é altamente concentrado na região Sudeste, com destaque às capitais dos estados" (Sidone; Haddad; Mena-Chalco, 2016, p.17).

Quanto aos aspectos do referencial teórico das teses e dissertações analisadas, a principal referência utilizada foi Serge Moscovici e suas obras, desenvolvidas ao longo dos anos, conforme pode ser observado no Tabela 4. Além de Serge Moscovici, 
Jean-Claude Abric, por meio de sua Teoria do Núcleo Central (TNC), foi o segundo autor mais referenciado nas teses e dissertações, seguido por Denise Jodelet e Sandra Jovchelovitch.

Tabela 4. referencial teórico das teses e dissertações que versam sobre as representações sociais e a Educação Física.

\begin{tabular}{|c|c|}
\hline Autor & Referencial Teórico \\
\hline Guarinon (2016) & Moscovici (2009). \\
\hline Triani (2015) & Moscovici (1978). \\
\hline Lobato (2015) & Moscovici (2003) e Abric (1976). \\
\hline Gregório (2014) & Moscovici (2013). \\
\hline Stroher (2014) & Moscovici (2003) e Jodelet (2001). \\
\hline Sales (2018) & Moscovici (2003). \\
\hline Jesus (2014) & Moscovici (2003) \\
\hline Sá (2015) & Moscovici (1978; 2011). \\
\hline Honorato (2017) & Moscovici (2009) e Abric (2001) \\
\hline Martins (2018) & Moscovici (2003) e Abric (2003). \\
\hline Lima (2013) & Moscovici (1978; 2003) e Abric (1998). \\
\hline Medeiros (2016) & Jodelet (1989) e Jovchelovitch (2000). \\
\hline Almeida (2017) & Moscovici (2012) e Abric (2001) \\
\hline Rosa (2019). & Moscovici (1978). \\
\hline Santos (2016). & Abric $(1998 ; 2001 ; 2003)$ \\
\hline Caramez (2016). & Moscovici (2001) e Jodelet (2001). \\
\hline Lima (2014). & $\begin{array}{l}\text { Moscovici }(2003 ; 2012) \text {, Jodelet }(2001) \text { e } \\
\text { Jovchelovitch }(2008 ; 2012) .\end{array}$ \\
\hline Savarezzi (2017). & Moscovici (1978) e Abric (1994; 2000). \\
\hline Monteiro (2016). & Moscovici (2011). \\
\hline Ordonio (2017). & Moscovici (2012). \\
\hline Varanda (2018). & Jodelet (2001). \\
\hline Costa (2017). & Não evidenciado. \\
\hline Siqueira (2019). & Moscovici (2015) e Jodelet (2001). \\
\hline Nascimento (2018). & Moscovici $(2013 ; 2015)$ \\
\hline Polati (2019). & Moscovici (2003) e Abric (2001) \\
\hline Martins (2014). & Moscovici (2009). \\
\hline Paula (2018). & Moscovici (1978) e Abric (1998). \\
\hline Engeroff (2016). & Moscovici (1978; 2009). \\
\hline
\end{tabular}

Fonte: Autores.

Perante a verificação do referencial teórico utilizado pelos autores dos trabalhos, evidenciou-se a adesão maioritária pela abordagem processual (ancoragem e objetivação) da TRS nas investigações na área da Educação Física. Em alguns trabalhos foram utilizadas tanto a abordagem processual quanto a abordagem estrutural (núcleo central e núcleo periférico) de Jean-Claude Abric.

A utilização dessas duas abordagens em uma mesma investigação é comumente observada em pesquisas que se apropriam da TRS para compreender determinado objeto, pois, conforme aponta Triani (2015, p.15), há pesquisadores que lançam mão de ambas as abordagens "[...] para dar conta dos objetivos estabelecidos na investigação". Sá (2002) esclarece que as correntes teóricas apresentadas por Jean-Claude Abric, Williem Doise e Denise Jodelet são complementares à teoria de Serge Moscovici. Dessa maneira, justifica-se a utilização de mais de uma abordagem nas investigações das representações sociais nos trabalhos analisadas. 
No que diz respeito aos aspectos metodológicos das teses e dissertações, verificamos que a abordagem qualitativa foi utilizada em todas as produções, sendo que em seis trabalhos os pós-graduandos fizeram uso em suas pesquisas tanto da abordagem qualitativa quanto da quantitativa.

Constatamos também que a maioria das pesquisas utilizaram questionários como instrumento de coleta de dados, e o segundo método mais usado foi técnicas de entrevistas. Contudo, destaca-se também a presença de outros instrumentos e técnicas, tais como: teste de associação livre de palavras, observação participante, grupo focal, técnicas de desenhos, análise documental, registro fotográfico, diário de campo e grupos de discussão, como pode ser visto no Tabela 5.

Em relação aos participantes, na maioria das pesquisas os sujeitos foram alunos da educação básica, seguido por professores da educação básica, acadêmicos do curso de Educação Física, gestores, um coordenador escolar e professores do ensino superior.

Tabela 5. Aspectos metodológicos das teses e dissertações sobre as representações sociais e a Educação Física.

\begin{tabular}{|c|c|c|c|}
\hline Autor & Abordagem & $\begin{array}{l}\text { Instrumento de Coleta de } \\
\text { Dados }\end{array}$ & Sujeitos \\
\hline $\begin{array}{l}\text { Guarinon } \\
\text { (2016). }\end{array}$ & Qualitativa. & Entrevista. & Alunos da educação básica. \\
\hline $\begin{array}{l}\text { Triani } \\
\text { (2015). }\end{array}$ & Qualitativa. & $\begin{array}{l}\text { Técnica projetiva do desenho } \\
\text { e teste de associação livre de } \\
\text { palavras. }\end{array}$ & $\begin{array}{c}\text { Acadêmicos de Educação } \\
\text { Física. }\end{array}$ \\
\hline $\begin{array}{l}\text { Lobato } \\
\text { (2015). }\end{array}$ & Qualitativa. & Questionário. & $\begin{array}{c}\text { Professores da educação } \\
\text { básica. }\end{array}$ \\
\hline $\begin{array}{l}\text { Gregório } \\
\text { (2014). }\end{array}$ & Qualitativa. & $\begin{array}{l}\text { Observação participante, } \\
\text { grupo focal, desenho e } \\
\text { entrevista. }\end{array}$ & Alunos da educação básica. \\
\hline $\begin{array}{l}\text { Stroher } \\
\text { (2014). }\end{array}$ & $\begin{array}{l}\text { Qualitativa e } \\
\text { quantitativa }\end{array}$ & Questionário. & $\begin{array}{c}\text { Acadêmicos de Educação } \\
\text { Física. }\end{array}$ \\
\hline $\begin{array}{l}\text { Sales } \\
\text { (2018). }\end{array}$ & Qualitativa. & Questionário e entrevista. & Alunos da educação básica. \\
\hline $\begin{array}{l}\text { Jesus } \\
\text { (2014). }\end{array}$ & Qualitativa. & Entrevista. & $\begin{array}{l}\text { Professores da educação básica } \\
\text { e coordenadora da educação } \\
\text { infantil. }\end{array}$ \\
\hline $\begin{array}{c}\text { Sá } \\
(2015) \text {. }\end{array}$ & Qualitativa. & Entrevista. & $\begin{array}{c}\text { Professores da educação } \\
\text { básica. }\end{array}$ \\
\hline $\begin{array}{l}\text { Honorato } \\
\text { (2017). }\end{array}$ & $\begin{array}{l}\text { Qualitativa e } \\
\text { quantitativa. }\end{array}$ & $\begin{array}{l}\text { Questionário e teste de } \\
\text { associação livre de palavras. }\end{array}$ & $\begin{array}{c}\text { Acadêmicos de Educação } \\
\text { Física. }\end{array}$ \\
\hline $\begin{array}{l}\text { Martins } \\
\text { (2018). }\end{array}$ & Qualitativa. & Questionário. & $\begin{array}{c}\text { Professores da educação } \\
\text { básica. }\end{array}$ \\
\hline $\begin{array}{l}\text { Lima } \\
\text { (2013). }\end{array}$ & Qualitativa. & Questionário. & $\begin{array}{l}\text { Professores e alunos da } \\
\text { educação básica. }\end{array}$ \\
\hline $\begin{array}{l}\text { Medeiros } \\
\text { (2016). }\end{array}$ & Qualitativa. & Observação participante. & $\begin{array}{c}\text { Professores da educação } \\
\text { básica. }\end{array}$ \\
\hline Almeida (2017). & Qualitativa. & Entrevista. & Professores do ensino superior. \\
\hline Rosa (2019). & Qualitativa. & $\begin{array}{l}\text { Questionário e teste de } \\
\text { associação livre de palavras. }\end{array}$ & Alunos da educação básica. \\
\hline $\begin{array}{l}\text { Santos } \\
(2016) \text {. }\end{array}$ & Qualitativa. & Questionário. & $\begin{array}{c}\text { Professores da educação } \\
\text { básica. }\end{array}$ \\
\hline Caramez (2016) & Qualitativa. & $\begin{array}{c}\text { Análise documental, } \\
\text { questionário e teste de } \\
\text { associação livre de palavras. }\end{array}$ & $\begin{array}{l}\text { Acadêmicos de Educação } \\
\text { Física. }\end{array}$ \\
\hline
\end{tabular}




\begin{tabular}{|c|c|c|c|}
\hline $\begin{array}{l}\text { Lima } \\
(2014) .\end{array}$ & Qualitativa. & Entrevista. & $\begin{array}{l}\text { Professores e alunos da } \\
\text { educação básica. }\end{array}$ \\
\hline $\begin{array}{l}\text { Savarezzi } \\
(2017)\end{array}$ & Qualitativa. & $\begin{array}{c}\text { Questionário e teste de } \\
\text { associação livre de palavras. }\end{array}$ & Alunos da educação básica. \\
\hline $\begin{array}{l}\text { Monteiro } \\
(2016)\end{array}$ & $\begin{array}{l}\text { Qualitativa e } \\
\text { quantitativa. }\end{array}$ & $\begin{array}{l}\text { Questionário, entrevista e } \\
\text { registro fotográfico. }\end{array}$ & $\begin{array}{c}\text { Professores da educação } \\
\text { básica. }\end{array}$ \\
\hline $\begin{array}{l}\text { Ordonio } \\
\text { (2017). }\end{array}$ & Qualitativa. & Questionário. & $\begin{array}{l}\text { Professores da educação } \\
\text { básica. }\end{array}$ \\
\hline $\begin{array}{l}\text { Varanda } \\
(2018)\end{array}$ & Qualitativa. & Questionário e grupo focal. & $\begin{array}{l}\text { Professores, alunos e gestores } \\
\text { da educação básica. }\end{array}$ \\
\hline $\begin{array}{r}\text { Costa } \\
(2017)\end{array}$ & $\begin{array}{l}\text { Qualitativa e } \\
\text { quantitativa. }\end{array}$ & Entrevista. & Alunas da educação básica. \\
\hline $\begin{array}{l}\text { Siqueira } \\
(2019)\end{array}$ & Qualitativa. & Entrevista. & Alunos da educação básica. \\
\hline $\begin{array}{l}\text { Nascimento } \\
\text { (2018). }\end{array}$ & Qualitativa. & Entrevista e grupo focal. & Alunos da educação básica. \\
\hline $\begin{array}{l}\text { Polati } \\
\text { (2019). }\end{array}$ & $\begin{array}{l}\text { Qualitativa e } \\
\text { quantitativa. }\end{array}$ & Questionário e entrevista. & $\begin{array}{c}\text { Acadêmicos de Educação } \\
\text { Física. }\end{array}$ \\
\hline $\begin{array}{l}\text { Martins } \\
\text { (2014). }\end{array}$ & Qualitativa. & $\begin{array}{l}\text { Entrevista e observação } \\
\text { participante. }\end{array}$ & Alunos da educação básica. \\
\hline $\begin{array}{l}\text { Paula } \\
(2018) .\end{array}$ & $\begin{array}{l}\text { Qualitativa e } \\
\text { quantitativa. }\end{array}$ & Questionário. & $\begin{array}{l}\text { Professores e alunos da } \\
\text { educação básica. }\end{array}$ \\
\hline $\begin{array}{l}\text { Engeroff } \\
(2016)\end{array}$ & Qualitativa. & $\begin{array}{c}\text { Entrevista, grupos de } \\
\text { discussão, observação } \\
\text { participante e diário de campo. }\end{array}$ & Alunos da educação básica. \\
\hline
\end{tabular}

Fonte: Autores.

Após essa contextualização das principais informações de caráter bibliométrico, as quais permitiram compreender as teses e dissertações selecionadas, faz-se necessário ponderar os principais resultados desses estudos.

Tabela 6. Principais resultados destacados pelos autores.

\section{Autor Principais resultados}

Guarinon A Educação Física é entendida como uma disciplina semelhante aos demais componentes

(2016). curriculares, diferenciando-se por possuir aulas práticas e teóricas. Os conhecimentos aprendidos são importantes por serem uteis no cotidiano informal. A motivação para participação nas aulas é por motivos estéticos, gosto pessoal pelos esportes e por razão normativa (notas/conceitos).

Triani Os indícios dos acadêmicos de Educação Física sobre o Corpo estão balizados na saúde,

(2015). movimento e bem estar, relacionando-se com corpos fisicamente fortes que buscam por meio do movimento um bem estar.

Lobato A mídia social Facebook influencia nas representações de Corpo de determinados indivíduos. As

(2015). representações sociais dos docentes sobre o Corpo estão relacionadas, sobretudo, à saúde.

Gregório As representações das crianças sobre o Corpo femininos não contemplam a pluralidade de corpos

(2014). existentes e se sustentam em características como: beleza, delicadeza e sensibilidade. As práticas corporais da Educação Física corroboram para a construção destas representações, mas também se apresentam como um espaço em que se pode questioná-las continuamente. As representações das crianças sobre corpos femininos não são definitivas, uma vez que se mostraram conflitantes e em construção.

Stroher "[...] a Atividade Física e a Saúde ainda são os principais objetivos do trabalho com o corpo/aluno (2014). nas aulas de Educação Física na escola, sob a óptica dos discentes". 
Sales As representações dos jovens do ensino médio sobre a Educação Física ainda se baseiam no (2018). esportivismo no contexto escolar e na busca por um Corpo padrão nas academias. Os jovens pesquisados reproduzem as representações construídas historicamente sobre a Educação Física.

Jesus A inserção da Educação Física na Educação Infantil de Serra/ES gerou tensões, como, por

(2014). exemplo, as disputas por espaços físicos e profissionais e a incompreensão da função do professor desse componente curricular. Todavia, as experiências nessa etapa escolar estão “[...] contribuindo para a ressignificação das representações, favorecendo a construção de leituras positivas desse contexto de atuação docente".

Sá As representações sociais dos professores indicam que ainda permanece entre os eles "[...] uma (2015). visão fragmentária de formação humana, levando a conclusão de que a ideia de formação integral presente nos documentos oficiais está longe de ser alcançada”.

Honorato "[...] as representações dos acadêmicos indicam que Ser Professor e Ser Professor de Educação

(2017). Física é ser uma pessoa responsável, dedicada e comprometida com a ação pedagógica”. O conceito de Educação Física Escolar está centrado no esporte e na saúde. A escolha pela profissão está relacionada às experiências na infância e adolescência.

Martins O lugar da Educação Física na Educação Infantil se encontra em constante disputa, cercada por

(2018). tensões e posições. Os indivíduos que compõem esse campo, “[...] convivem, agem e reagem em função das diversas contingências expressas nos documentos oficiais, nas produções acadêmicascientíficas, nos currículos de formação e nos discursos docentes".

Lima “[...] as práticas de lazer dos alunos na escola se aproximam das atividades de educação física e

(2013). das artes”. No que tange à educação integral, as representações dos docentes “[...] apontam para preocupações com o currículo e com as práticas pedagógicas, o que é próprio da organização do trabalho na escola. Já os alunos ressaltam a ampliação do tempo para estudar na escola, o que refere maior preocupação com alteração do ritmo cotidiano".

Medeiros As representações sociais dos professores estão ligadas à compreensão "[...] de que a autonomia

(2016). do professor de Educação Física está relacionada ao pedagógico. O estudo também demonstra que em contextos com modelos de gestão "vertical” a autonomia tem menor possibilidade de ser integral".

Almeida Observou-se determinada similaridade no percurso formativo dos professores, formando uma

(2017). espécie de padrão comum com algumas variações. Nas representações dos professores, a Licenciatura em Educação Física não possui linhas de pesquisa bem definidas, ocasionado, assim, ao campo da Educação Física Escolar dificuldades de evoluir com consensualidade.

Rosa As representações sociais dos alunos sobre as lutas relacionam-se à agressividade e à violência

(2019). em todos os grupos pesquisados pelo autor, independente do gênero ou de experiências prévias com a modalidade.

Santos “[...] os professores de Educação Física Escolar possuem uma visão genérica sobre o (2016). desenvolvimento da criança, construída, sobretudo, na ênfase do aspecto motor”.

Caramez "[...] as representações sociais de formação pedagógica dos discentes das duas Universidades

(2016). podem estar em processo de elaboração, pois eles parecem não ter muitas informações sobre as disciplinas de conteúdo pedagógico e ainda as desvalorizam [...]”, pois sugerem a exclusão dessas do currículo.

Lima No que tange à Capoeira, o autor constatou que "[...] diversos sentidos são representados por um

(2014). mesmo sujeito e que as diferentes posições ocupadas pelos sujeitos exercem influência na representação assumida".

Savarezzi Foram percebidas semelhanças no núcleo das representações sociais dos alunos do ensino

(2017). fundamental e do médio sobre a Educação Física, pois houve a presença das cognições "Exercícios", "Esporte", "Futebol" e "Vôlei" nas representações dos alunos de ambas as etapas. Quanto às diferenças, aparecem os termos "Brincar", "Legal" e "Correr" no núcleo das representações dos alunos do fundamental, enquanto dos alunos do ensino médio aparece o termo "Saúde".

Monteiro “[...] as representações dos professores caracterizam a profissão como bonita e útil, que exige

(2016). criatividade; porém, é desvalorizada, pesada e sem reconhecimento social. Em contraposição, a profissão é valorizada e reconhecida pela comunidade rural”. Os professores pesquisados 
percebem a zona rural como um lugar atrasado, “[...] reduzem o currículo e reforçam estereótipos que desvalorizam a cultura e a identidade dos moradores da roça”.

Ordonio “[...] os resultados indicam que as representações sociais sobre psicomotricidade ancoram-se em

(2017). grande parte no modelo educativo, que reconhece o conhecimento da psicomotricidade enquanto ferramenta que ajuda no desenvolvimento integral (social, afetivo, motor) do aluno".

Varanda “[...] os resultados mostram que cada grupo possui uma concepção de Educação Física, sendo que

(2018). alguns deles compartilham suas concepções, e que termos como esporte, brincadeiras, movimento são associados à área em todos os grupos”.

Costa " "...] as desigualdades de gênero presentes na sociedade exercem influência também nas aulas de

(2017). Educação Física, e se manifestam através da disciplinarização de corpos, dos diferentes tipos de comportamentos entre alunos e alunas, além da seleção e direcionamento dos conteúdos aos gêneros". As ações decorrentes da desigualdade de gênero são determinantes para a autoexclusão das alunas nas aulas de Educação Física.

Siqueira [...] a análise dos dados aponta que no $5^{\circ}$ ano os alunos já manifestam sobre a transição para o $6^{\circ}$ (2019). ano como um momento difícil. Ao entrarem no $6^{\circ}$ ano, a sensação de transição e mudança foi percebida por todos os alunos entrevistados". A escola pesquisada se mostrou um ambiente de relações pessoais intensas e com um convívio desafiador. "[...] com relação à Educação Física no $6^{\circ}$ ano, observa-se o excesso de aulas na sala, textos e apostila, contudo a relação professor/aluno bem como a metodologia, conciliando teoria e prática, se mostrou importante para assegurar a participação e o interesse dos alunos pelas aulas".

Nascimento "Os resultados acusam que as representações sociais do Corpo perante a Educação Física são (2018) reveladas para a formação de hábitos de condicionamento físico e aquisição de habilidades esportivas". As representações sobre o Corpo contribuem para que determinados alunos apresentem resistência em participar das aulas devido à expectativa corporal criada.

Polati "A centralidade das representações foi associada à burocracia para a formalização do estágio

(2019). devido ao excesso de documentos, assinaturas, custos financeiros com fotocópias e deslocamentos entre IES e escola”. Todavia, na periferia há evocações que condizem com a proposta pedagógica do estágio supervisionado, "[...] relevando a prática como espaço de aprendizagem da docência por meio da socialização com agentes escolares e alunos da educação básica, aquisição de experiência e construção de identidade profissional, incidindo no reconhecimento do valor pedagógico do ECS".

Martins Constatou-se que as representações sobre a Educação Física estão alicerçadas na promoção da

(2014). saúde. A aplicação da proposta pedagógica foi avaliada de maneira positiva, “[...] sendo fator primordial para este resultado o planejamento, sistematização e diversificação nas aulas. Portanto, a interpretação das Representações Sociais da disciplina Educação Física forneceu indícios para a elaboração da proposta pedagógica, que se apresentou como uma criação metodológica de trabalho específica para esses jovens e adultos, evidenciando uma das diversas formas de ensino possibilitando a concretização de uma nova dinâmica para o currículo da Educação Física inserida na EJA".

Paula As representações sociais sobre o Corpo nas aulas de Educação Física estão “[...] ancoradas

(2018). esferas, tais como: a relacional, a étnica, a de gênero, a dos materiais utilizados como recursos pedagógicos, a da esportivização, a da não diversificação de atividades-conteúdos; a da sistematização dessas aulas; e a do prazer. E objetivadas, de modo respectivo, na forma de desenhos de alunos: em relação a outro(s) corpo(s) e a elemento(s) do espaço; com a tez de pele branca; com o gênero masculino; relacionando-se com materiais convencionais, de modo particular, com o elemento bola; praticando esportes, mormente, o futebol; realizando somente uma atividade-conteúdo; desempenhando atividades sistematizadas; e com semblantes demonstrando satisfação, prazer”.

Engeroff Entende-se que há “[...] práticas, representações e elementos que fazem com que a EFI repita

(2016) práticas já enraizadas nas concepções higienista, militarista e esportivista, mas também parece haver elementos que a direcionam para outros caminhos". Entretanto, as representações sobre a 
Educação Física, “[...] estão atreladas umas às outras na medida em que se uma se move, a outra também vai sofrendo alterações”.

Fonte: Autores.

Os principais resultados apresentados no Tabela 6 foram retirados dos resumos das teses e dissertações. Optamos por apresentar alguns trechos dos resultados na íntegra devido ao fato de estes sintetizarem de maneira clara e objetiva as conclusões a que chegaram os pós-graduandos em suas investigações.

\section{Considerações Finais}

A comparação entre o número de teses e dissertações encontradas nesta pesquisa de revisão bibliográfica com o número apresentado por Triani e Novikoff (2014) - oito trabalhos entre 2000 e 2012 e 28 entre 2013 e 2020 - evidencia que nos últimos anos houve uma adesão considerável à TRS pelos pós-graduandos ao pesquisarem temas relacionados à Educação Física no âmbito escolar. Todavia, salientamos que, diante da importância do estudo das representações sociais na área educacional, é necessário maior apropriação dessa teoria pelos pesquisadores que debruçam suas investigações sobre a área da Educação Física, tal como evidencia Honorato (2017) em sua tese de doutorado.

O crescimento do número de trabalhos defendidos em cursos de mestrado e doutorado com a temática investigada nessa pesquisa comprova o interesse crescente dos pesquisadores em compreender os aspectos psicossociais no âmbito educacional, tal como destacado em pesquisa realizada por Souza e Villas Bôas (2011). Esse fato tem permitido que os estudos sobre as representações sociais adquiram cada vez mais espaço na educação e que a psicossociologia se firme como um dos campos de grande valia para a compreensão dos fatores que permeiam os ambientes escolares.

Destacamos a necessidade da realização de pesquisas que analisem as outras áreas de atuação da Educação Física em que estudos sobre as representações sociais estão sendo desenvolvidos, os quais não foram analisados nesta pesquisa devido ao fato de o escopo da investigação se restringir ao âmbito educacional.

\section{Referências}

Abric, J. C. (2001). O estudo experimental das representações sociais. In: Jodelet, D. As representações sociais. Eduerj.

Aguiar, R. S. (2003). A Educação Física nas séries iniciais do ensino fundamental: importância dessa prática para o desenvolvimento integral na fase escolar. Anais do Congresso Mercosul de Cultura Corporal e Qualidade de Vida. Brasil, 3.

Alves-Mazzotti, A. J. (1994). Representações Sociais: aspectos teóricos e aplicações à Educação. Revista Em Aberto, Brasília, 14 (61), 60-78. https://doi.org/1 0.24109/2176-6673.emaberto.14i61.1944.

Freitas, W. C.; Triani, F. S.; Novikoff, C. (2017). Representações sociais de estudantes do ensino médio sobre a Educação Física. Revista Brasileira de Psicologia do Esporte, Brasília, 7 (2), 13-25. http://dx.doi.org/10.31501/rbpe.v7i2.7950.

Gomes, I. et al. (2018) O Corpo como tema da produção do conhecimento: uma análise bibliométrica em cinco periódicos da Educação Física brasileira. Movimento (ESEFID/UFRGS), Porto Alegre, 2 (2), 427-440. https://doi.org/10.22456/1982-8918.73701.

Honorato, I. C. R. (2017). As representações sociais de acadêmicos do curso de Licenciatura em Educação Física sobre o que é ser professor. Tese de doutorado, Universidade Estadual de Ponta Grossa, Ponta Grossa, PR, Brasil.

Jodelet, D. (2001). Representações sociais: um domínio em expansão. In JODELET, D. As representações sociais. Eduerj.

Lovisolo, H. (2002). Da educação física escolar: intelecto, emoção e corpo. Motriz, Rio Claro, 8 (3), 99-103. http://www.rc.unesp.br/ib/efisica /motriz/ 08n3/Lovisolo.pdf.

Mello, A. S. et al. (2012). Representações sociais sobre a Educação Física na Educação Infantil. Revista da Educação Física/UEM, Maringá, 23 (3), $443-455$. https://doi.org/10.4025/reveducfis.v23i3.12684. 
Research, Society and Development, v. 10, n. 4, e11710414017, 2021

(CC BY 4.0) | ISSN 2525-3409 | DOI: http://dx.doi.org/10.33448/rsd-v10i4.14017

Moreira, J. S. \& Miranda, E. O. (2019). Teoria das Representações Sociais: a epistemológica para a educação. Revista Multidisciplinar em Educação, Porto Velho, 6 (15), 98-113. https://doi.org/10.26568/2359-2087.2019.3562.

Moscovici, S. (2003). O Fenômeno das Representações Sociais. In. Representações sociais: investigações em psicologia social, Vozes.

Oliveira, M. S. B. S. (2001). Representações Sociais: uma teoria para a sociologia? Revista Estudos de Sociologia, 7 (1),71-94. https://periodicos.ufpe.br/revis tas/revsocio/article/view/235454.

Pereira A. S. et al. (2018). Metodologia da pesquisa científica. UFSM. https://repositorio.ufsm.br/bitstream/handle/1/15824/Lic_Computacao_MetodologiaPesquisa-Cientifica.pdf?sequence $=1$.

Sá, C. P. (2002). Núcleo central das representações sociais (2a ed.) Vozes.

Sidone, O. J. G., Haddad, E. A. \& Mena-Chalco, J. P.A. (2016). A ciências nas regiões brasileiras: evolução da produção e das redes de colaboração científica. Transinformação, 28 (1), 15-32. https://doi.org/10.1590/2318-08892016002800002.

Souza, C. P. \& Villas Bôas, L. P. S. (2011). A Teoria das Representações Sociais e o estudo do trabalho docente: os desafios de uma pesquisa em rede. Revista Diálogo Educacional, 11 (33), 271-286. http://dx.doi.org/10.7213/rde.v11i33.4285.

Triani, F. S. (2015). As Representações Sociais de Estudantes de Educação Física sobre o Corpo. Dissertação de mestrado, Universidade de Grande Rio, Duque de Caxias, RJ, Brasil.

Triani, F. S., Magalhães Júnior, C. A. O. \& Novikoff, C. (2017). As representações sociais de estudantes de Educação Física sobre a formação de professores. Revista Movimento, 23 (2), 575-586. https://doi.org/10.22456/1982-8918.68898.

Triani, F. S. \& Novikoff, C. (2014). As formas de valoração e afrontamento na formação de professores (inicial) dos estudantes dos cursos de educação física. Revista Práxis, 6 (11), 95-101. https://doi.org/10.25119/praxis-6-11-612.

Varanda, S. S. (2018). As representações sociais de Educação Física na visão de diferentes atores escolares: alunos, professores e gestores. Dissertação de mestrado, Universidade Estadual Paulista Júlio de Mesquita Filho, Rio Claro, SP, Brasil.

Vasconcelos, F. F., \& Campos, P. H. F. (2014). Ancoragem da representação social da Educação Física escolar nas abordagens teóricas da Educação Física. Motrivivência, 26 (43), 164-182. https://doi.org/10.5007/2175-8042.2014v26n43p164. 